\title{
El cine documental de Claude Lanzmann. El Holocausto contado a partir de Shoah
}

\author{
Elios MENDieTa RodRíGueZ \\ Universidad Complutense de Madrid \\ eliosmr@gmail.com
}

\begin{abstract}
RESUMEN
Desde que filmara el documental Shoah, en 1985, Claude Lanzmann no ha dejado de crear piezas cinematográficas que resultan fundamentales para entender el desarrollo del pensamiento historiográfico de la segunda mitad del pasado siglo. Su particular forma de contar el horror, por medio de los testimonios, es un camino fidedigno de contar la realidad. Ante este modo narrativo, han surgido diversos discursos críticos, que también serán tratados. Lo cierto es que la influencia de la obra de Lanzmann ha sido capital, y este trabajo pretende, a partir de esta, acercarse al Holocausto con el cine documental como herramienta propicia para ello. De este modo, se realizará un estudio de las características cinematográficas desarrolladas por el director desde Shoah hasta El último de los injustos, su último filme estrenado hasta la fecha.
\end{abstract}

Palabras clave: Lanzmann, Shoah, Cine, Documental, Holocausto, Guerra.

\section{Documentary Cinema of Claude Lanzmann. The Holocaust counted from Shoah}

\begin{abstract}
Since he filmed the documentary Shoah, in 1985, Claude Lanzmann has not stopped filmaking pieces that are essential to understand the development of the historiographical thought in the second half of the last century. His particular way of telling the horror, through the testimonies, is a reliable way to tell the reality. Given this narrative mode, there have been different critical discourses which also they will be analyzed. The truth is that the influence of Lanzmann's work has been capital, and this work aims to make an approach to the Holocaust with the documentary film as a suitable tool for it. Therefore, a study of film features developed by the director will be made from Shoah to Le dernier des injusted, his last work to date.
\end{abstract}

Keywords: Lanzmann, Shoah, Cinema, Documentary, Holocaust, War. 


\section{Introducción}

Claude Lanzmann llega tarde al cine, pues tiene 40 años cuando rueda su primera película. No obstante, hoy en día es ampliamente conocido, sobre todo por Shoah, el filme que centra el presente estudio. Son muchas las razones que hacen que este documental, de más de nueve horas de duración, esté siempre presente; ya sea por ser una gran obra sobre «la solución final» empleada por el régimen nazi para el exterminio de los judíos, o bien por el eterno debate entre la conveniencia de la imagen representada o no representada del Holocausto, o ya sea por la cantidad de películas que se estrenan al año sobre esta temática. Lo que parece claro es que Shoah establece un punto y parte, no solo en la forma de contar el horror, sino también en los cimientos del cine documental como herramienta. Aunque se estrenó en 1985, Lanzmann comienza su proceso de creación once años atrás, almacenando más 350 horas de rodaje, cuyo metraje queda reducido en sala de montaje, finalmente, a las casi diez horas de duración en las que se extiende el documental. A través de las víctimas, funcionarios y testigos se profundiza en el tema, sin un ápice de espectacularización, y sin usar imágenes de archivo del horror, pues el francés considera que es tal el nivel de barbarie que se alcanzó entre 1939 y 1944 que es imposible e inadmisible representarlo.

Antes de realizar el análisis del filme documental y de introducirse en el universo cinematográfico del director, es conveniente reseñar brevemente la figura de Lanzmann. Nace en 1925, en Bois-Colombes (Francia), e hijo de unos padres procedentes de Besaravia, la actual Moldavia, Lanzmann pronto sufre la invasión nazi, y tiene que desplazarse a la región gala de Auvernia, donde experimenta el desarrollo del antisemitismo. En la capital de esta región, Clermont-Ferrand, se une al maquis en 1943 y participa en la Resistencia. Al final de la guerra, se marcha a Alemania, donde ejerce de profesor en la Universidad Libre de Berlín dividido. En 1952, es invitado por Jean-Paul Sartre a colaborar en Les temps modernes $^{1}$, una revista de la que se hace cargo en 1986, tras la muerte de Simone de Beauvoir. Una década antes había llegado al cine, con Pourquoi Israel ${ }^{2}$, que se estrena en 1972, y que retrata la sociedad existente en el primer cuarto de siglo de vida del joven estado de Israel.

\section{Shoah: Análisis de la gran obra del Holocausto}

Shoah es una de las grandes narraciones del Holocausto. Desde su estreno, se comporta como una pieza irreductible. Una obra que renuncia a las imágenes inter-

${ }^{1}$ Claude Lanzmann es el director actual de la revista fundada por Sartre, por lo que, en este 2016, se ha cumplido el treinta aniversario del creador francés como director de la mítica revista.

${ }_{2}$ Es una película en el que se denotan ciertos tintes políticos, que el director nunca negó, y en la que el Holocausto también empieza a tener un peso simbólico, y con el que se empieza a ver ese cinematógrafo polemista que es en la actualidad y que ha sido desde que aterrizara en el mundo del séptimo arte. 
puestas para centrarse en el rostro de quienes lo vivieron, y tomando como margen los lugares que lo acogieron. Una especie de oxímoron, pues es una extraordinaria narración testimonial de lo que allí aconteció, pero en la que se preserva el misterio de un acontecimiento que Lanzmann califica de inabarcable y obsceno si se pretende explicar. «Estamos ante la construcción de un auténtico monumento (en el que el mármol ha sido sustituido por el celuloide) en el sentido fuerte de esta palabra» (Zumalde et al., 2010: 93) escribe el crítico Santos Zunzunegui sobre la obra del francés. Con su cine, Lanzmann preserva el potencial que un acontecimiento como «la solución final» tiene para inflamar la memoria y la conciencia, para dejar claro que es una barbarie, un hecho que produjo un dolor sin igual y que, precisamente, si se apela a esta memoria y conciencia, es la única forma de no olvidar, para que nunca más se vuelva a repetir algo así.

Analizar Shoah no es una tarea sencilla. Se ha de tener en cuenta la cinta como un todo, tanto por su duración, temática, metodología empleada, estética escogida, enorme ambición y por su inquebrantable verdad en forma y fondo. Y, por supuesto, por su particular estructuración:

El proceso varía según las tres categorías de personajes que aparecen en Shoah. Están las víctimas, judíos, que son todas personas muy particulares. Son hombres que pertenecieron a los «comandos especiales», a los que elegí sólo porque todos ellos tendrían que haber estado muertos [...] Con los nazis era otra cosa. A los nazis primero había que encontrarlos. Cada nazi que aparece en Shoah es un milagro, porque por principio todos se niegan a hablar y más delante de una cámara. Todos los que aparecen en la película fueron filmados con una cámara oculta, sin que ellos lo supieran. Y por último, los polacos, con los que todo fue muy diferente. Era fundamental no matar su espontaneidad. Suponen la parte western de la película: el primer hombre que vuelve al lugar del crimen. (Exteberría y Cabrerizo, 2010) ${ }^{3}$

A estos tres grupos; víctimas, verdugos y testigos, no les otorga el mismo tratamiento, por lo que Lanzmann no cultiva la parcialidad. El primer grupo, el de los judíos, es el más abundante, pues en torno a los testimonios de estos construye la narración. Son palabras duras, que evocan dolor y crudeza, y que están montadas sin un ápice de sentimentalismo. Muchos de estos miembros de este primer grupo pertenecieron a los comandos especiales, como los sonderkommandos ${ }^{4} \mathrm{o}$ los judenrat ${ }^{5}$, es decir, aquellos judíos con ciertos privilegios. El segundo conjun-

${ }^{3}$ Entrevista a Claude Lanzmann realizada por Jon Exteberría y Felipe Cabrerizo, disponible online en la bibliografía final.

${ }^{4}$ Estos se encargaban de ciertas tareas como recoger los cadáveres de las cámaras de gas o de inspeccionar entre las ropas de los enviados a estas cámaras con el propósito de hallar objetos de valor. Este grupo es fidedignamente retratado en la valiosa y reciente película El hijo de Saúl (2015), dirigida por el húngaro Laszlo Nemés.

5 Eran los miembros de los consejos de judíos que, en cada campo, establecía el régimen nazi. Autores como Primo Levi han considerado a los miembros de los judenrat como colaboracionistas y, por tanto, traidores. Sin embargo, Lanzmann, en toda su filmografía, le da un trato bastante positivo, incluso de héroes. 
to sería el de los verdugos. Lanzmann reconoce que fue el componente más difícil de conseguir, pues ninguno quería hablar a la cámara directamente, por lo que tuvo que hacerlo con el método de la cámara oculta. Por último está el bloque de los testigos, del que se puede destacar como principal característica la espontaneidad de sus declaraciones.

La relevancia testimonial del documental es muy grande en varios trozos del filme. Un caso claro y especial es de Abraham Bomba, que ejercía de peluquero en los campos de concentración, y su misión, en esta máquina de matar que era el entramado nazi, era la de cortar el pelo a todo aquel que, acto seguido, iba a ser mandado a morir a la cámara de gas. Bomba, para el testimonio, es enviado a una peluquería, donde pese a estar ya retirado, Lanzmann consigue que cuente sus recuerdos mientras corta el pelo. Son unas declaraciones desgarradoras, pues Bomba asegura que si hubiese contado algo de lo que les esperaba él hubiese sido, de inmediato, enviado a las cámaras:

Así es como paso el día. Veinticuatro horas sin agua, sin nada, no podíamos beber nada, llevar nada a nuestra boca, era imposible. Solo pensar que un minuto, una hora antes, formabas parte de una familia, una mujer, un marido. Y, de repente, de golpe, todo había muerto. (Lanzmann, 2001: 55) ${ }^{6}$

Y todo esto, por tanto, en una barbería, mientras ejerce su antigua profesión, en un día nublado y sin introducir ningún elemento cinematográfico que pueda banalizar los hechos. Una puesta en escena buscada y muy cuidada por parte de Lanzmann: «Testimonio que es puesto en escena por Lanzmann en una operación mayéutica [...]. De esta manera, Lanzmann se coloca a sí mismo -y, de golpe, coloca al espectador en idéntica posición- en la que aquel que no ha visto. Porque se trata de eso: de ver y saber» (Zumalde et al., 2010: 91).

Si es relevante la estructuración de los testimonios, no lo es menos la importancia del contexto geográfico, esto es, de los paisajes en los que se rueda. En ocasiones, aparecen los paisajes en el filme sobre los que se escucha, sin que se muestre el rostro o la figura de quien emite las palabras, la voz en off de quienes están hablando. Lanzmann concede así un papel protagonista a estos, ya vacíos, ausentes, que en su día albergaron la masacre, la barbarie. Va a existir una retroalimentación, por lo tanto, entre la palabra dicha por los testimonios y los paisajes mostrados:

Existe una lucha, y una colaboración al mismo tiempo, entre la imagen y la palabra. Lo que oímos da al paisaje una dimensión que no tendría por sí mismo. La palabra añade algo, crea un desasosiego, un extrañamiento, compone una interrogación sobre el paisaje. Pero al mismo tiempo el paisaje confiere a la palabra una extraña fuerza, una fuerza quizá mayor que si las voces estuviesen siempre sincronizadas con los rostros. (Exteberría y Cabrerizo, 2010)

${ }^{6}$ Claude Lanzmann publicó, en 2001, el libro Shoah, en el recoge todas las declaraciones testimoniales aparecidas en la película homónima. Es por eso que, en vez de usar el guión original de la película, por eficacia a la hora de consultar, las citas se extraen de este libro. 
No obstante, y en este claro juego de imágenes y palabras, perviven la ausencia y el vacío. Lanzmann construye una imagen de lo que, por definición, carece de la misma, como es la llamada «solución final». Es, por tanto, la representación de un caso de exterminio extremo, esto es, la representación del intento fallido nazi de eliminar físicamente a los judíos, y ocultarlo todo, convirtiéndolos en algo inexistente.

Por tanto, la importancia de los testimonios y los paisajes es capital para analizar Shoah, pero lo que hace particularmente distinto a este inmenso proyecto es la moral de la representación que establece Lanzmann en el desarrollo cinematográfico de la cinta, y que luego extrapolará a sus restantes obras. Esta forma de representación supone la seña de identidad de todo su cine, y se erige como una especie de biblia de cómo se ha de mostrar el horror, que cuenta con numerosos seguidores y detractores ${ }^{7}$, que tiene en el lenguaje cinematográfico su más fiel aliado. Por tanto, junto al tratamiento de los testimonios y paisajes, son otras las características que definen la moral de la representación del cine de Lanzmann, y que están presentes en Shoah:

A) La no inclusión de imágenes de archivo en sus más de nueve horas de metraje. Este es el principal caballo de batalla desde el estreno de la cinta. Alimentado por el propio Lanzmann, el debate de la representación o no de la imagen del Holocausto ha estado en boga, prácticamente, desde el fin de la Segunda Guerra Mundial. El punto álgido del debate, ya entrado el presento siglo, aconteció tras la publicación de Imágenes pese a todo (2003), un libro del filósofo e historiador de arte Georges Didi-Huberman ${ }^{8}$. Lanzmann reniega de la inclusión de este tipo de imágenes y de la ficción como método para explicar el horror. Para él, la imagen de archivo siempre es falsa. Esto lo ha explicado en reiteradas ocasiones, y dice que «la shoah» fue un acontecimiento demasiado monstruoso para ser reflejado con eficacia y sin caer en inmoralidades por el séptimo arte, a menos que lo haga como lo hace él en sus trabajos, esto es, sin caer en invenciones. De ahí que el creador francés se autoerija como único guardián de la correcta representación del Holocausto, y que ataque sin piedad a todas las películas que han planteado este tema desde una posición distinta a la suya.

Para Claude Lanzmann, la única forma posible de representar el Holocausto es la que él ensayó en Shoah, su documental de 1985: ninguna imagen puede contarnos esa historia, de modo que no debe mostrarse ni una sola toma de archivo, y solo queda dar voz a los sobrevivientes. (Burucúa y Kwiatkowski, 2015: 17)

B) Rechazar toda forma de pathos. Es decir, la máxima aristotélica de usar los sentimientos para afectar los sentimientos de los destinarios del mensaje, en este

7 En el punto 4 del presente trabajo, se aborda, con mayor profundidad, el debate de la conveniencia o no de la representación de la imagen.

${ }^{8}$ En Imágenes pese a todo, Didi-Huberman habla de la importancia de la imagen de archivo, pues explica que, tan solo con una, y por muy fragmentada, difusa o solitaria que fuese, ya serviría para explicar el horror. Algo que nunca ha compartido Lanzmann, y que dejó por escrito en una columna publicada en Le Monde, en 1994, tras el estreno de La lista de Schindler de Spielberg, que titulo: «Holocausto: la representación imposible». 
caso. Es por eso que no añade ningún elemento extra cinematográfico que altere la percepción que en el espectador provocan los testimonios de los protagonistas. Es el caso del elemento sonoro, pues en ningún momento se utiliza la música junto a las palabras de los personajes, lo que podría crear una alteración sustancial de los sentimientos.

C) Total protagonismo del rostro. La cámara refleja la cara de los entrevistados en toda su plenitud. Así, Lanzmann hace del rostro del personaje la pantalla sobre la que se interpreta el drama de lo relatado, en donde va a importar la enunciación de los hechos. Es la forma que tiene el director francés de otorgar respeto para con sus entrevistados, independientemente de que sean testigos, víctimas o verdugos.

D) El propio Lanzmann como conductor de las entrevistas. Dice haber creado la mejor pieza documental sobre el Holocausto y un trabajo inigualable. Esta vanidad explica que el creador galo se sienta partícipe de lo que cuenta, pero como un mero espectador y, eso sí, manteniendo siempre el respeto ante los testimonios que escucha. Lanzmann estructura el orden de la palabra frente a la tentación que genera el silencio.

E) Mantener una cercanía con el entrevistado. Esto queda patente en la organización del plano interior. En las conversaciones, Lanzmann aparece en el plano, y se ve cómo realiza las preguntas, y muestra cómo recibe la información que emana de sus testimonios. Aunque en ocasiones el propio Lanzmann aparezca fuera de campo, se intuye su cercana presencia por su voz en off, lo que hace que el entrevistado nunca esté solo, y que se alimente una cercanía patente.

\section{Las piezas cinematográficas de Lanzmann tras Shoah}

Como expone Zunzunegui, Lanzmann es el creador de un monumento en el que el celuloide sustituye el mármol. Pero no es Shoah su única pieza. Se trata de un conjunto de monumentos fílmicos, que ha fragmentado y dilatado espacial y temporalmente, hasta crear más películas en torno a esta masacre, a las que, a cada una, ha imprimido su propio carácter. Así, su obra completa hasta la fecha -su último trabajo data de 2013- es inigualable dentro del cine documental y esencialmente compacta. Gran parte del metraje de estas películas posteriores a Shoah devienen de entrevistas filmadas, en principio, para ser incluidas en la obra magna, pero que por una u otra razón fueron descartadas. Son cuatro las producciones posteriores que se centran en estos lager: Alguien vivo pasa (1997), Sobibor, 14 de octubre de 1943, 16 horas (2001), The Karski Report (2010) y El último de los injustos (2013). Con este archipiélago de textos consigue decir cinematográficamente lo que parecía imposible.

En los primeros minutos de Alguien vivo pasa, Lanzmann alude razones estructurales y de duración para no haber incluido los testimonios de esta cinta en Shoah. Esta se centra en entrevistas con Maurice Rossel, un diplomático suizo, perteneciente a la Cruz Roja, que inspeccionó en 1944 el gueto checoslovaco de Terezín y el campo de Auswitchz, dando un informe totalmente falso, pues escribía que el trato dado a los prisioneros en ambos lager era positivo. El galo le muestra al final de la cinta su incredulidad, y le llega a recriminar no haber estado nunca allí. 
El segundo texto fílmico de este póker es Sobibor, 14 de octubre de 1943, 16 horas, cuya entidad es mayor. En este ensalza la figura de Yehuda Lerner, un mito de la resistencia, un judío que encabezó la revuelta del campo de concentración de Sobibor a la hora y en la fecha a la que alude el título de la cinta. Existen grandes momentos narrativos en esta película, y Lanzmann no va a ser dudoso: se muestra muy a favor de las declaraciones constantes de Lerner, al que va a considerar una especie de héroe. Es el caso de la secuencia en que relata, el propio Lerner, como emprendió la huida. El cineasta recrea este hecho y parece disfrutar mientras escucha su narración.

La escenografía de Lanzmann, guiada por la voz de Lerner, actúa con una impulsión sonora fortísima: ahoga a su vez la voz del narrador como antaño ahogó las voces del horror. Es como una siniestra repetición: lo que antaño se hizo con la voz humana actualmente se perpetra con la palabra del testigo. (Sánchez-Biosca, 2007: 143)

Luego estrenaría The Karski Report ${ }^{9}$, cuyo protagonista, a diferencia de las dos anteriores, si había tenido presencia en Shoah. El protagonista es Jan Karski, antiguo miembro de la resistencia polaca, que narra cómo le contó a Franklin D. Roosevelt en 1943, por aquel entonces presidente de los Estados Unidos de América, lo que había visto en el gueto de Varsovia. En este, Lanzmann denuncia el poco crédito que desde instituciones gubernamentales neutrales se le dio a las declaraciones de alarma que se empezaban a verter en estos años, como es el caso de las realizadas por Karski ${ }^{10}$.

Mi propio trabajo es arduo y exigía mucho de mí. Todos los días me reunía con dos o tres hombres muy involucrados en la Resistencia. Llevábamos a cabo estas entrevistas sin ignorar que la Gestapo bien podía estar rondando por allí. Tenía que intercambiar opiniones con estos hombres acerca de montones de temas, explicar las posturas y pareceres de otros jefes clandestinos y averiguar cuáles eran las suyas propias, así como tomar nota de sus reacciones y sus decisiones, para comunicar todo ello una vez más. (Karski, 2011: 379)

La última película de Lanzmann, hasta la fecha, es El último de Los injustos ${ }^{11}$, estrenada en 2013, con el realizador a punto de entrar en su novena década de vida. De estas cuatro películas posteriores a Shoah, quizás sea la más importante por dos motivos fundamentales: su enorme duración -se extiende hasta los 220 minutos- y la inclusión de imágenes de archivo, con lo que rompe así su fuerte credo de no

9 Estrenada en la televisión francesa, posteriormente es llevada a la gran pantalla.

${ }^{10}$ La historia contada aquí por el creador francés procede de un libro escrito por el propio Jan Karski, en 1945: Historia de un estado clandestino. La editorial Acantilado tradujo la obra, al castellano, en 2011. En el libro cuenta todos los detalles e historias que le sobrevinieron en su estancia en el gueto de Varsovia, y describe la importancia de hacer de correo entre el gobierno polaco en el exilio y la resistencia interior. Según Karski, solo cuenta lo que él mismo ha vivido, visto y escuchado.

${ }_{11}$ El título, aunque sacado de unas declaraciones del propio Murmelstein, evoca la novela El último justo, de André Schwart-Bart, sobre el futuro y la suerte de una familia judía. 
incluir este tipo de imágenes en sus documentales ${ }^{12}$. En el filme, Lanzmann recupera unas entrevistas que había realizado, de nuevo para Shoah, a Benjamín Murmelstein, quien fue el último presidente del campo de concentración de Terezín. Casi cuarenta años después, el cineasta francés monta el filme en torno a estas preguntas, pero va a aparecer también el Lanzmann actual, que va a visitar, en persona, el campo de concentración. Entre las imágenes de 1975 y la visita de Lanzmann en 2012 a este campo de concentración, el paso del tiempo se convierte en un elemento imprescindible, que juega un peso importante en la concepción de la memoria que se hace el espectador tras el visionado de la propia película.

\section{El debate de la representación de la imagen del Holocausto}

Aunque toma fuerza a principios del presente siglo, Lanzmann pone en boga el debate sobre la conveniencia o no de la representación de la imagen tras estrenar Shoah. Aunque es justo advertir que este debate ya había aparecido antes. Es el caso de Adorno, que en sus muy conocidas declaraciones, habla de la imposibilidad de hacer poesía tras Auschwitz. Tampoco hay que olvidar las duras críticas que el recientemente fallecido director de la Nouvelle Vague, Jacques Rivette, vierte sobre la cinta Kapó, dirigida por el italiano Gillo Pontecorvo, al que acusó de tramposo, pues aseguraba que la escena del suicidio de Enmanuella Riva era «abyecta».

No obstante, la corriente crítica al discurso de la no representación de Lanzmann toma fuerza, como se ha dicho, con la publicación de Imágenes pese a todo, en 2003, por lo que el historiador de arte Didi-Huberman se convirtió en su principal estandarte. En el libro, habla de cuatro fotografías tomadas en el campo de exterminio de Auschwitz-Birkenau, presumiblemente, por Alex, un miembro del sonderkommando, y las analiza y se pregunta cómo esta fuente visual puede ayudar en el entendimiento de la barbarie: «Hay imágenes de la Shoah que, si no lo dicen todo -y aún menos 'el todo'- de la Shoah, son de todos modos dignas de ser miradas e interrogadas como hechos característicos y como testimonios de pleno derecho de esta trágica historia» (Didi-Huberman, 2003: 102).

Sin duda, este discurso de la representación es el que más adeptos tiene, y es algo que muestra la historia de la cinematografía y las artes. La primera gran película en hablar abiertamente del Holocausto fue, probablemente, Niebla y noche (1955) de Alain Resnais ${ }^{13}$. Esta obra incluye material fotográfico y fílmico que fue donado por diversas instituciones, aunque también incluye planos grabados en los campos de Auschwitz y Maidanek. Este filme, en palabras de Vicente SánchezBiosca, en su libro Cine de Historia, cine de memoria. La representación y sus límites, actualiza el presente en un recorrido donde se conjugan los travellings con el metraje de archivo.

12 Al ser preguntado por ello, Lanzmann explica que lo ha hecho porque anhela sentirse libre.

13 En esta aparece el escritor Jean Cayrol, un superviviente de los campos, y de sus poemas Poemes de la nuit et de brouillard deviene el título de la obra. 
No obstante, Lanzmann no ha estado solo en esta pugna intelectual. Tras la publicación de la citada obra de Didi-Huberman, aparecieron defensores del discurso capitaneado por el padre de Shoah. Es el caso del ensayista y psicoanalista Gerard Wajcman, que en su libro El objeto del siglo se propone, precisamente, encontrar cuales han sido, en términos artísticos, los productos u objetos que definen este siglo XX. Junto a la Rueda de Bicicleta de Duchamp (1913), o el Cuadrado negro sobre fondo blanco, de Malevich (1913), entre otros, el documental Shoah es para Wajcman uno de los productos que mejor describe la pasada centuria.

Por último, en 2015, ocurre algo inaudito: un producto consigue poner de acuerdo a las dos partes. El hijo de Saúl, la película dirigida por Laszlo Nemes consigue enormes alabanzas tanto de Lanzmann como de Didi-Huberman. El primero, tras el paso de la película por el Festival de Cannes, declara sentirse admirado ${ }^{14}$, mientras que el segundo llega a escribir una carta al director húngaro. Esta misiva luego se convierte en el libro Sortir du Noir (2016): «Votre film, Le Fils de Saul, est un monstre. Un monstre nécessaire, cohérent, bénéfique, innocent. Le resultat d' un pari esthétique et narratif extraordinairement risqué» (Didi-Huberman, 2016: 7).

\section{Conclusión}

Independientemente del debate moral surgido sobre lo conveniente de representar la imagen del horror, Shoah es, por su dimensión, alcance y proyección, la gran obra del Holocausto. Un filme épico, que demuestra la valía del cine documental como herramienta narrativa. Un gran retrato filmado sobre la llamada «solución final», la gran barbarie del pasado siglo. Un cineasta que pretende hacer Historia y que lo consigue, y que, con esta, acaba haciendo poesía, desmintiendo así a Adorno. Y lo hace con una espiral de testimonios que dan una medida cercana a lo que pasó, pues saber en totalidad lo que ocurrió, como el propio Lanzmann ha dicho siempre, es incalculable. El gran relato occidental del pasado siglo, el Holocausto, tiene en Claude Lanzmann su narrador principal, y en Shoah y las posteriores cintas del francés, su gran legado.

\section{Referencias bibliográficas}

Bou, Stéphane (2014): «El monumento y su arquitecto». Caimán. Cuadernos de cine. № 74 : pp. 28-29.

14 El periodista de El País Alex Vicente recoge las declaraciones de Lanzmann tras ver la película en Cannes: «A diferencia de la falacia que presentó Spielberg, que no reflexionó suficientemente sobre la cuestión, Nemes nunca muestra las cámaras de gas. No ha querido representar el Holocausto, sino la vida de los Sonderkommandos. En su película, la gente corre sin descanso, entre gritos constantes de fondo. La nobleza de Nemes consiste en no haber querido seducirnos. Al revés: la suya es una película muy tosca». Artículo disponible en: http://cultura.elpais.com/cultura/2016/01/08/actualidad/1452266477_763745.html 
BurucúA, José Emilio y KWIATKOWsKI, Nicolás (2015): Como sucedieron estas cosas. Representar masacres y genocidios. Buenos Aires: Katz Editores.

Didi-Huberman, Georges (2004): Imágenes pese a todo. Paidós: Barcelona.

Didi-Huberman, Georges (2015): Sortir du Noir. París: Les Éditions de Minuit.

EXTEBERRÍA, Jon y CABRERIZO, Felipe (2010): «Solo existe la vida. Entrevista con Claude Lanzmann». Minerva: Revista del Círculo de Bellas Artes. № 15: pp. 23-27. [en línea]: http://www.circulobellasartes.com/revistaminerva/articulo.php?id=424 Último acceso: 15/06/16.

KARSKI, Jan (2011): Historia de un Estado clandestino. Barcelona: Acantilado.

LANZMANN, Claude (2003): Shoah. Madrid: Arena Libros.

SÁNCHEZ-BIOSCA, Vicente (2006): Cine de historia, cine de memoria. La representación y sus límites. Madrid: Cátedra.

SÁNCHEZ-BIOSCA, Vicente (2007): «La representación y lo inhumano». Quintana: Revista de estudios do Departamento de Historia da Arte. $\mathrm{N}^{\mathrm{o}}$ 6: pp. 139-148. [en línea]: http://www.redalyc.org/articulo.oa?id=65323956010 Último acceso: 15/06/16.

WAJCMAN, Gerard (2001): El objeto del siglo. Buenos Aires: Amorrortu.

Zumalde, Imanol, ARocenA, Carmen y ZunZunEGui, Santos (2010): Imágenes del otro: el cine de en la comprensión de la discriminación. Revista Venezolana de Información, Tecnología y Conocimiento. $\mathrm{N}^{\mathrm{0}}$ 7: pp. 79-94. [en línea]: http://www.redalyc.org/articulo.oa?id=82312576006 Último acceso: 15/06/16.

\section{Filmografía}

Le dernier des injustes (2013): Película dirigida por Claude Lanzmann. Francia/ Austria, Synecdoche, Le Pacte, Dor Film Produktionsgesellschaft [DVD].

Le Rapport Karski (2010): Película dirigida por Claude Lanzmann para la televisión francesa. Francia, Arte [DVD].

Saul fia (2015): Película dirigida por Laszlo Nemes. Hungría, Laokoon Filmgroup [DVD].

Shoah (1985): Película dirigida por Claude Lanzmann. Francia, Les Films Aleph, Ministère de la Culture de la Republique Française [DVD] -Parte 1 y Parte 2-.

Sobibór, 14 octobre 1943, 16 heures (2001): Película dirigida por Claude Lanzmann. Francia, France 2 Cinéma, Les Films Aleph, Why Not Productions [DVD].

Un vivant qui passé (1997): Película dirigida por Claude Lanzmann. Francia, La Sept-Arte, Les Films Aleph, MTM Cineteve [DVD]. 